\title{
Optimum Design of a Hybrid PV/Wind Energy System Using Genetic Algorithm (GA)
}

\author{
Satish Kumar Ramoji ${ }^{1}$, Bibhuti Bhusan Rath ${ }^{2}$, D.Vijay Kumar ${ }^{3}$ \\ ${ }^{I}$ (PG Student, Dept. of E.E.E., AITAM, Tekkali, Andhra Pradesh, India, \\ ${ }^{2}$ (Assoc. Prof., Dept. of E.E.E., AITAM, Tekkali, Andhra Pradesh, India, \\ ${ }_{3}^{3}$ (Prof. \& H.O.D., Dept. of E.E.E., AITAM, Tekkali, Andhra Pradesh, India,
}

\begin{abstract}
In this paper, a new approach of optimum design for a Hybrid PV/Wind energy system is presented in order to assist the designers to take into consideration both the economic and ecological aspects. When the stand alone energy system having photovoltaic panels only or wind turbine only are compared with the hybrid $\mathrm{PV} /$ wind energy systems, the hybrid systems are more economical and reliable according to climate changes. This paper presents an optimization technique to design the hybrid PV/wind system. The hybrid system consists of photovoltaic panels, wind turbines and storage batteries. Genetic Algorithm (GA) optimization technique is utilized to minimize the formulated objective function, i.e. total cost which includes initial costs, yearly replacement cost, yearly operating costs and maintenance costs and salvage value of the proposed hybrid system. A computer program is designed, using MATLAB code to formulate the optimization problem by computing the coefficients of the objective function. The method mentioned in this article is proved to be effective using an example of hybrid energy system. Finally, the optimal solution is received using Genetic Algorithm (GA) optimization method.
\end{abstract}

Keywords: - Battery, Genetic Algorithm, Hybrid PV/Wind energy system, Optimization, and wind energy

\section{INTRODUCTION}

Global environmental concerns and the ever-increasing need for energy, coupled with a steady progress in renewable/green energy technologies, are opening up new opportunities for utilization of renewable energy resources. In particular, advances in wind and photovoltaic (PV) generation technologies have increased their use in wind-alone, PV-alone, and hybrid PV-wind configurations. Moreover, the economic aspects of these renewable energy technologies are sufficiently promising at present to include the development of their market [1]. A hybrid energy system consists of two or more energy systems, energy storage system, power conditioning equipment, and a controller. Hybrid energy systems may or may not be connected to the grid. They are generally independent of large centralized electric grids and are used in rural remote areas [2-4]. In many remote areas of the world, the availability, reliability, and cost of electricity supplies are major issues. The standard solution is typically to use diesel or petrol generators to meet power requirements in areas distant from established electricity grids (Sustainable Energy Development Office 2010). There can be a number of problems with running stand-alone diesel or petrol generation, including noise, pollution, and high running and maintenance costs. Generators can also be inconvenient to use. Due to the high running and maintenance costs, continuous operation of a generator may not be financially viable [5]. The use of hybrid energy systems, incorporating PV and wind resources, in remote locations can overcome or at least limit some of the problems associated with generator only systems. The use of these renewable energy-based systems could help reduce the operating cost through the reduction in fuel consumption, increase system efficiency, and reduce noise and emissions [6]. But such PV-wind hybrid systems are usually equipped with diesel generators to meet the peak load demand during the short periods when there is a deficit of available energy to cover the load demand [6, 7]. To eliminate the need of a diesel generator, a battery bank can be used. Battery life is enhanced when batteries are kept at near $100 \%$ of their capacity or returned to that state quickly after a partial or deep discharge [7]. The use of PV modules only does not protect batteries against deep discharges. During periods of little or no sunshine, the load draws more energy than the PVs can replace. A more dynamic source of energy is a wind turbine. Adding a wind turbine to a system would protect batteries against deep discharges and thus extend their life [7-9]. Many studies have been carried out in the area of sizing of PV-wind hybrid energy systems. Generally, there are three main approaches to achieve the optimal configurations of such hybrid systems in terms of technical analysis and economic analysis. These approaches are the iteration approach [7-13], the probabilistic approach [14], and the trade-off approach [15]. However, these approaches are time-consuming and difficult to adjust if insolation, wind speed, load demand, rating of each generator, and initial cost of each component are changed. In this paper, a genetic algorithm (GA) optimization technique is used to optimally size a proposed PV-wind hybrid energy system, by minimizing the total cost of the proposed hybrid system. 


\section{HYBRID SYSTEM STRUCTURE}

Fig. - 1 shows the proposed optimization procedure of the PV-Wind hybrid system based on high resolution solar irradiance including the cost analysis.

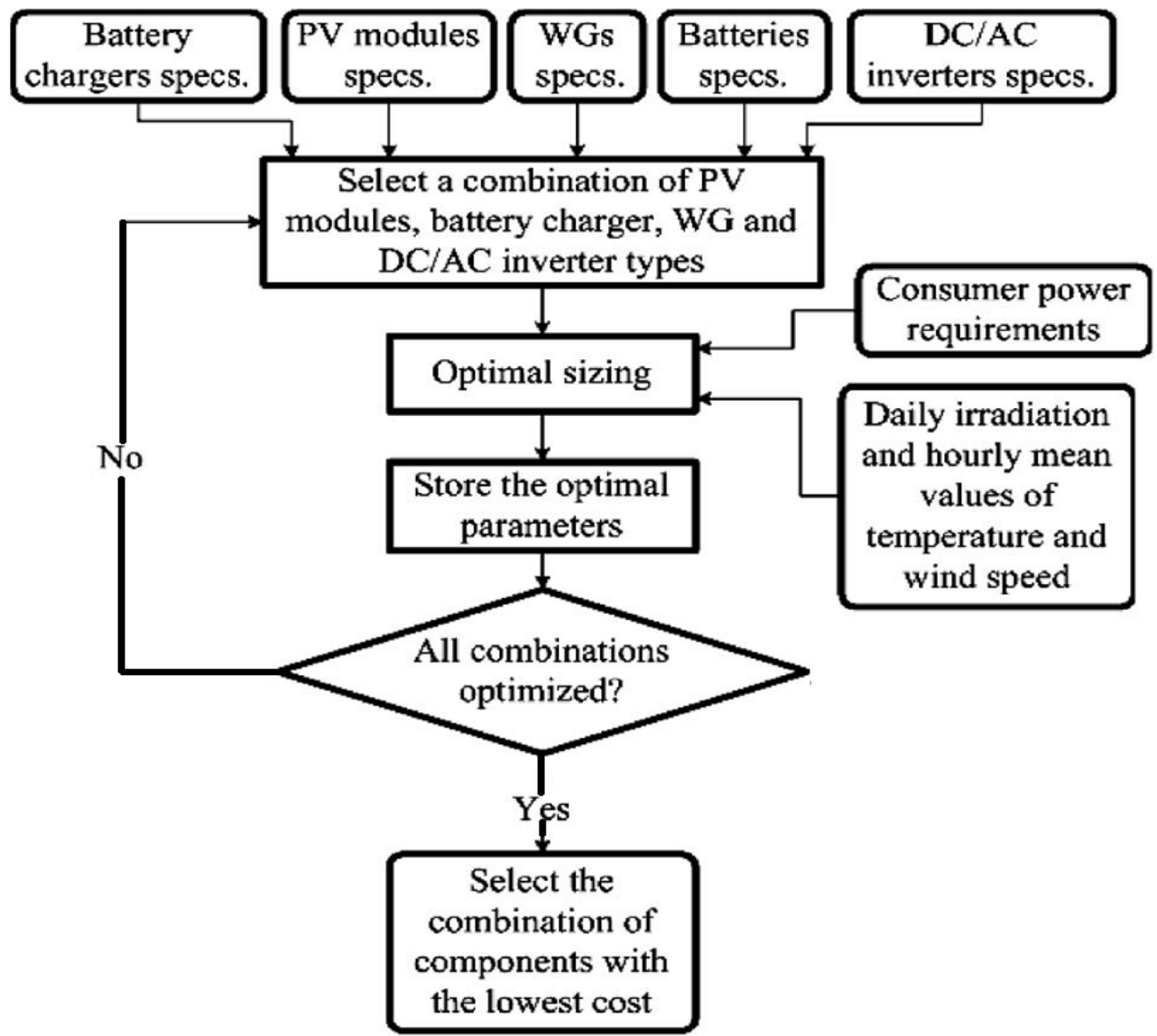

Figure -1: Flowchart of the proposed optimization methodology

The suggested approach employs a technical assessment in conjunction with cost-per-watt to select and size the PV panel, wind turbine, and battery storage in order to determine the system that would guarantee a reliable energy supply with the lowest investment. Figure -2 shows the general schematic of the hybrid system. The system can be divided into three main stages; the first stage is the generation which includes the PV and wind systems. The second stage is the conversion and storage energy system. The conversion system includes the DC/DC converter for the PV system, the AC/DC converter for the wind generators, and DC/AC inverter which is connected to the DC bus and supplies the $440 \mathrm{~V} \mathrm{AC}$ power to the load. The third stage is the grid connected load, where the $60 \%$ of the demand is supplied by the hybrid system.

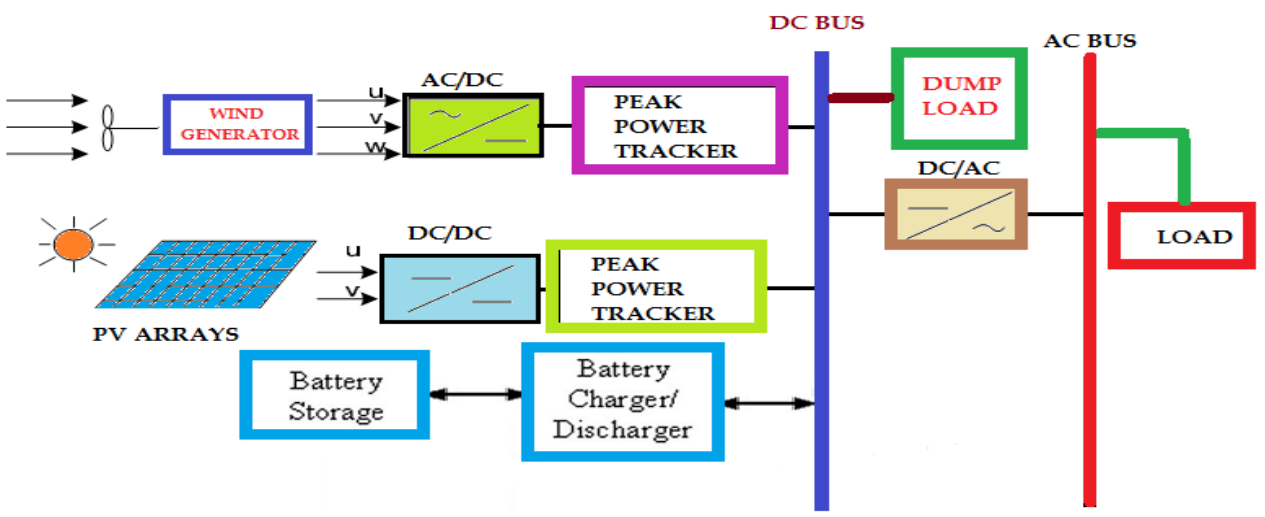

Figure -2: Structure of PV/Wind Hybrid System 


\section{METEOROLOGICAL AND LOAD DATA}

The proposed method is to optimally size a PV-wind hybrid energy system to electrify a residential remote area household near to latitude is $39.74^{\circ} \mathrm{N}$, Longitude $105.18^{\circ} \mathrm{W}$, Time Zone: - GMT-7, Elevation: $1829 \mathrm{~m}$. MIDC/NREL Solar Radiation Research Laboratory (BMS) is a good source for the long-term monthly average daily solar radiation data (incident on both horizontal and south-facing PV array tilted by the latitude angle $\phi$ of the site) and wind speed data (measured at 42 feet $/ 12.8 \mathrm{~m}$ height in the site). The proposed method requires a recorded long-term wind speed data and global insolation data (incident on a south-facing PV array tilted by the site latitude angle $\phi$ ) for every day of each month in a period of 1 year. Figures 3 and 4 show these data (i.e., the global solar insolation and wind Speed, respectively) for every month in a typical year. Figure 5 illustrates the considered residential remote area load profile, during the 12 months of the year.

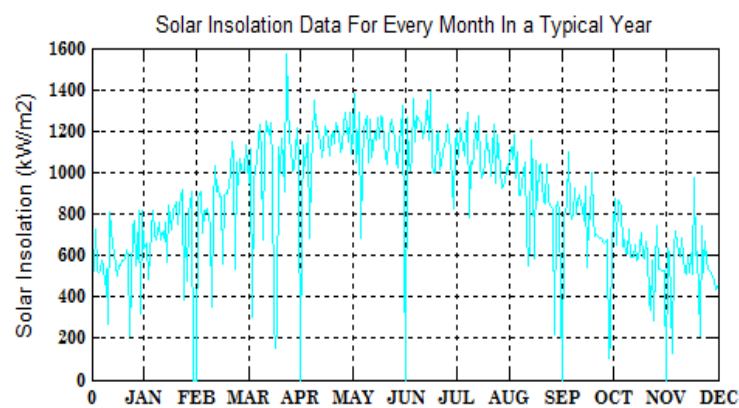

Figure -3: Global Solar Insolation
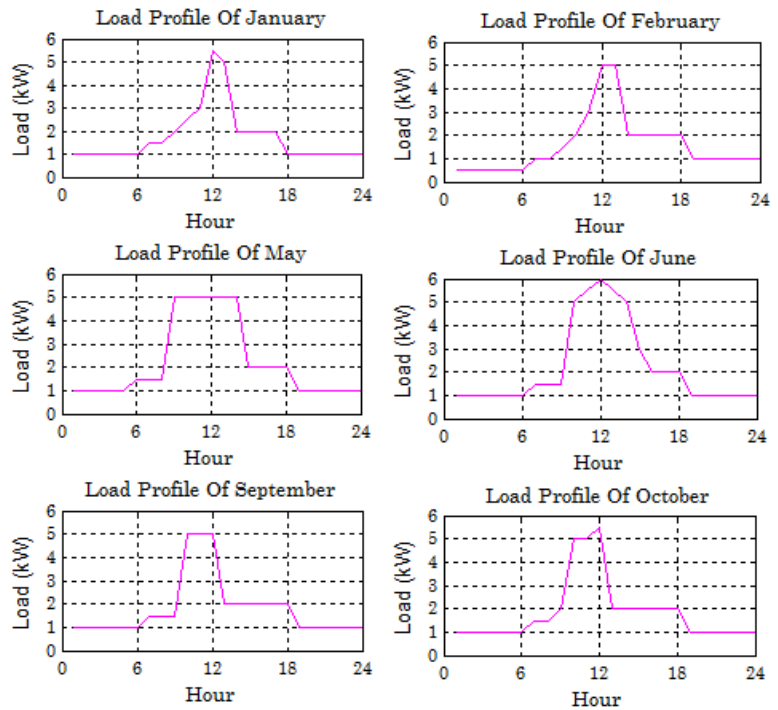

Figure -5: Load profile for all months of a typical year
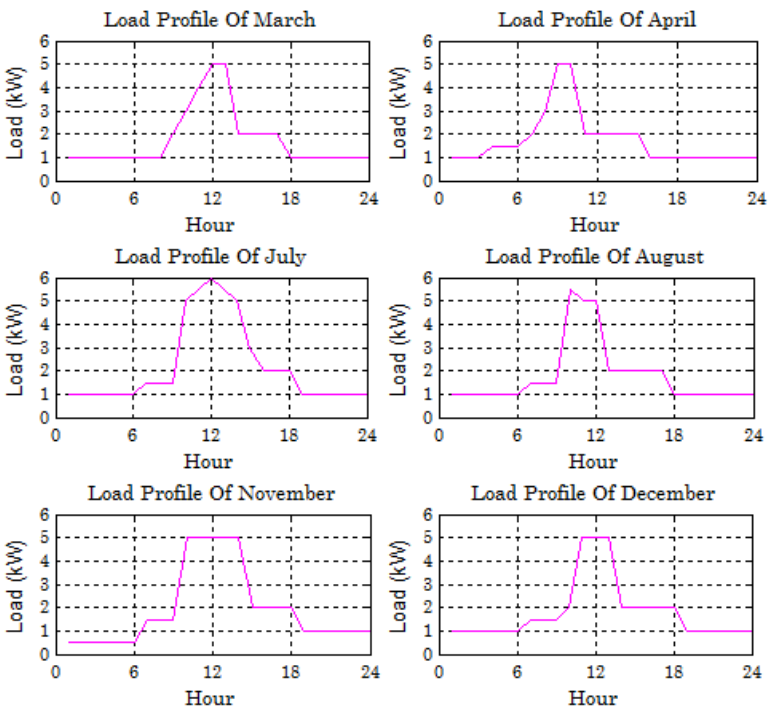

\section{PROBLEM FORMULATION}

The major concern in the design of the proposed PV-wind hybrid energy system is to determine the size of each component participating in the system so that the load can be economically and reliably satisfied. Hence, the system components are found subject to: 1. minimizing the total cost $\left(\mathrm{C}_{\mathrm{T}}\right)$ of the system, 2.ensuring that the load is served according to certain reliability criteria. The objective function $\left(\mathrm{C}_{\mathrm{T}}\right)$ is to be minimized, and this cost function is generated by the summation of the present worth (PWs) of all the salvage values of the equipment, the yearly operation and maintenance costs, the initial or capital investments, and the replacement costs of the system components. Thus, the objective function can be formulated as:

$$
\min . C \mathrm{~T}=\sum_{k=1}^{\mathrm{a}} I_{k}+R_{P W k}+O M_{P W k}-S_{P W k}
$$

Where the index $\mathrm{k}$ is to account for PV, wind, and batteries; $\mathrm{I}_{\mathrm{k}}$ is the capital or initial investment of each component $\mathrm{k}$; $\mathrm{R}_{\mathrm{PWk}}$ is the $\mathrm{PW}$ of the replacement cost of each component $\mathrm{k}$; $\mathrm{OM}_{\mathrm{PWk}}$ is the $\mathrm{PW}$ of the operation and maintenance costs of each component $\mathrm{k} ; \mathrm{S}_{\mathrm{PWk}}$ is the $\mathrm{PW}$ of the salvage value of each component 
$\mathrm{k}$. The constraints that ought to be met, while minimizing the objective function $\mathrm{C}_{\mathrm{T}}$, should ensure that the load is served according to some reliability criteria.

\section{IV.1. Basic Economic Considerations}

As Equation (1) suggests, the PWs of some annual payments as well as of salvage values are needed. Thus, assuming a life horizon of $N$ years for the project, an interest rate $r$, and an inflation rate $j$ (caused by increases in prices), the different PWs can be calculated as follows [16]: -

\section{IV.1.1: Salvage Value}

If a component has a salvage value of $S$ (Rs.) at present (because it is reaching the end of its life cycle), then the salvage value of the component is expected to be $S(1+j)^{N}$ (i.e., $N$ years from now provided that the component is put in service at the present time). The PW of $S(1+j)^{N}$ taking the interest rate into consideration, is

$$
S_{P W}=\frac{S_{\cdot}(1+j)^{N}}{(1+r)^{N}}
$$

Let fac1 $=(1+j)^{N} /(1+r)^{N}$, then $\mathrm{S}_{\mathrm{PWk}}=\mathrm{S}_{\mathrm{k}}$ facl, for all components $k$ in the hybrid system.

\section{IV.1.2: Operation and Maintenance}

If the operating and maintenance cost of a component is OM (Rs./year), then this tends to escalate each year at a rate not necessarily equal to the general inflation rate. Thus, for an escalation rate es the operation and maintenance costs incurred at year $y$ will be OM $(1+\mathrm{es})^{\mathrm{y}}$, and having a PW of : $\mathrm{OM}(1+e s)^{\mathrm{y}} /(1+r)^{\mathrm{y}}$

The summation of the PWs of all the annual payments is, thus, given by:

$$
\mathrm{OM}_{\mathrm{PW}}=\mathrm{OM} \cdot \sum_{y=1}^{N} \frac{(1+e s)^{y}}{(1+r)^{y}}=\mathrm{OM} \cdot \mathrm{fac} 2
$$

Where fac 2 represents a geometric progression, and is given by:

$$
\begin{gathered}
\text { fac2 }=\left(\frac{1+e s}{r-e s}\right) \cdot\left[1-\left(\frac{1+e s}{r-e s}\right)^{N}\right], r \neq e s \\
\mathrm{~N}, \quad \mathrm{r}=\mathrm{es}
\end{gathered}
$$

Hence, $\mathrm{OM}_{\mathrm{PWk}}=\mathrm{OM}_{\mathrm{k}}$. fac2, for all components $k$ in the system. Note that other PW calculations will be treated in a similar manner throughout the analysis of each component.

\section{IV.2. Total Cost Coefficients}

\section{IV.2.1: The PV Array}

Assuming the design variable, in case of the PV array, to be the total array area $A_{P V}$ in square meters. This area is constrained by both the maximum available area for the PV

Array (e.g., the roof surface of buildings) and the budget preset for the PV modules. With an initial cost of $\alpha_{\mathrm{PV}}$ (Rs. $\left./ \mathrm{m}^{2}\right)$, the total initial investment would be:

$$
I_{1}=\alpha_{\mathrm{PV}} \cdot A_{\mathrm{PV}}
$$

Note, here, that if the project life span is assumed to be the same as the PV array lifetime, then the replacement cost of the PV modules will be negligible (i.e., $\mathrm{R}_{\mathrm{PW} 1}=0$ ). With a yearly operation and maintenance cost of $\alpha_{\mathrm{OMPV}}$ (Rs. $/ \mathrm{m}^{2} /$ year), the total yearly operation and maintenance cost would be $\mathrm{OM}_{1}=\alpha_{\mathrm{OMPV}}$. $\mathrm{A}_{\mathrm{PV}}$. Thus, the global PW of the yearly operation and maintenance cost would be

$$
\mathrm{OM}_{\mathrm{PW} 1}=\alpha_{\mathrm{OMPV}} \cdot \mathrm{A}_{\mathrm{PV}} \cdot \text { fac2 }
$$

The salvage value can be found by multiplying the selling price per square meter $S_{P V}$ by the area $A_{P V}$, and the PW of the selling price would be

$$
\mathrm{S}_{\mathrm{PW} 1}=\mathrm{S}_{\mathrm{PV}} \cdot \mathrm{A}_{\mathrm{PV}} \cdot \mathrm{fac} 1
$$

In summary, the PWs of the PV array costs are:

$$
\begin{gathered}
\mathrm{I}_{1}+\mathrm{R}_{\mathrm{PW} 1}=\alpha_{\mathrm{PV}} \cdot \mathrm{A}_{\mathrm{PV}}=\mathrm{c}_{1} \cdot \mathrm{A}_{\mathrm{PV}} \\
\mathrm{OM}_{\mathrm{PW} 1}=\alpha_{\mathrm{OMPV}} \cdot \mathrm{A}_{\mathrm{PV}} \cdot \mathrm{fac} 2=\mathrm{c}_{2} \cdot \mathrm{A}_{\mathrm{PV}} \\
\mathrm{S}_{\mathrm{PW} 1}=\mathrm{S}_{\mathrm{PV}} \cdot \mathrm{A}_{\mathrm{PV}} \cdot \mathrm{fac} 1=\mathrm{c}_{3} \cdot \mathrm{A}_{\mathrm{PV}}
\end{gathered}
$$

\section{IV.2.2: The Wind Turbine}

The design variable due to the use of the wind turbine is the total rotor swept area $A_{w}$ in square meters. This value is constrained by both the space available and the budget of the project. Note that if $A_{w}$ is known, then it is the task of the designer to distribute $A_{w}$ among several machines such that the summation of the individual areas gives $A_{w}$. Since the lifetime of a wind turbine $L_{w}$ is usually shorter than that of the PV array $N$, then it might be necessary to purchase additional wind turbines before the life span of the project comes to an 
end. The number of times, within $N$ years, a wind turbine is needed is $X_{w}=N / L_{w}$ (rounded to the greater integer). If $\alpha_{\mathrm{w}}$ is the price in Rs. $/ \mathrm{m}^{2}$ at present, the price at year $y$ would be $\alpha_{\mathrm{w}} \cdot(1+\mathrm{es})^{\mathrm{y}}$ having the PW of $\alpha_{\mathrm{w}} \cdot(1$ $+e s)^{y} /(1+r)^{y}$. Thus, the PW of all the initial and replacement investments in wind turbines is

$$
\mathrm{I}_{2}+\mathrm{R}_{\mathrm{PW} 2}=\alpha_{\mathrm{w}} \cdot \mathrm{A}_{\mathrm{w}} \sum_{x=1}^{X_{w}} \frac{(1+e s)^{[x-1]} L_{W}}{(1+r)^{(x-1) L_{W}}}
$$

Where $e s$ is the escalation rate, $r$ is the interest rate, $L_{w}$ is the lifetime of wind turbines, and $X_{w}$ is the number of times wind turbines are purchased. Note that if $X_{w}$ equals 1 (i.e., the life span of the wind turbines is greater than or equal to that of the whole project), then $R_{P W 2}=0$ and $\mathrm{I}_{2}=\alpha_{\mathrm{w}} . \mathrm{A}_{\mathrm{w}}$ (since the wind turbines are bought once at the beginning of the project). With a yearly operation and maintenance cost of $\alpha_{\mathrm{OMw}}$ (Rs. $/ \mathrm{m}^{2} /$ year), the total yearly operation and maintenance cost would be $\mathrm{OM}_{2}=\alpha_{\mathrm{OMw}} \cdot \mathrm{A}_{\mathrm{w}}$, and the PW of all the yearly costs would be:

$$
\mathrm{OM}_{\mathrm{PW} 2}=\alpha_{\mathrm{OMw}} \cdot \mathrm{A}_{\mathrm{w}} \cdot \text { fac2 }
$$

The salvage value of the wind turbine is assumed to decrease linearly from $\alpha_{\mathrm{w}}\left(\mathrm{Rs} . / \mathrm{m}^{2}\right)$ to $\mathrm{S}_{\mathrm{w}}\left(\mathrm{Rs} . / \mathrm{m}^{2}\right)$, when the wind turbine operates along its lifetime $\mathrm{L}_{\mathrm{w}}$ (i.e., from its installation to the end of its lifetime, respectively). If the project life comes to an end before the wind turbines have reached the end of their life span, then the wind turbines could be sold at $S_{p w}\left(R s / \mathrm{m}^{2}\right)$, which is a value greater than $S_{w}$.

$$
\mathrm{S}_{\mathrm{pw}}=\left(\frac{\left(S_{w g}-a_{v g}\right.}{L_{w g}}\right) . \text { Years }+\alpha_{\mathrm{w}}
$$

Where "years" indicates the number of years of operation between the installation of the last wind turbine and the end of the project life span. Therefore, the PW of all the salvage values is found by:

$$
\mathrm{S}_{\mathrm{PW} 2}=\mathrm{S}_{\mathrm{w}} \cdot \mathrm{A}_{\mathrm{w}} \sum_{x=1}^{X_{w w}-1}\left(\frac{(1+j)^{x L_{\mathrm{v}}}}{(1+r)^{x L_{w}}}\right)+\mathrm{S}_{\mathrm{pw}} \cdot \mathrm{A}_{\mathrm{w}}\left(\frac{(1+j)^{\mathrm{N}}}{(1+r)^{N}}\right)
$$

If $N$ (i.e., the life span of the project) is a multiple of that of the wind turbines $L_{w}$, then Equation (12) can be reduced to

$$
\mathrm{S}_{\mathrm{PW} 2}=\mathrm{S}_{\mathrm{w}} \cdot \mathrm{A}_{\mathrm{w}} \sum_{x=1}^{X_{w}}\left(\frac{(1+j)^{x L_{\mathrm{w}}}}{(1+r)^{x L^{w}}}\right)
$$

In summary, the PWs of the wind turbine are:

$$
\begin{aligned}
& \mathrm{I}_{2}+\mathrm{R}_{\mathrm{PW} 2}=\alpha_{\mathrm{w}} \cdot \mathrm{A}_{\mathrm{w}} \sum_{x=1}^{X_{w}} \frac{(1+\varepsilon g)^{(x-1)} \cdot L_{w g}}{(1+v)^{(x-1) / h_{w}}}=\mathrm{c}_{4} \cdot \mathrm{A}_{\mathrm{w}} \\
& \mathrm{OM}_{\mathrm{PW} 2}=\alpha_{\mathrm{OMw}} \cdot \mathrm{A}_{\mathrm{w}} \cdot \mathrm{fac} 2=\mathrm{c}_{5} \cdot \mathrm{A}_{\mathrm{w}} \\
& \mathrm{S}_{\mathrm{PW} 2}=\mathrm{S}_{\mathrm{w}} \cdot \mathrm{A}_{\mathrm{w}} \sum_{x=1}^{X_{w w}-1}\left(\frac{(1+j)^{x L_{W}}}{(1+r)^{x L_{w}}}\right)+\mathrm{S}_{\mathrm{pw}} \cdot \mathrm{A}_{\mathrm{w}}\left(\frac{(1+j)^{N}}{(1+r)^{N}}\right)=\mathrm{c}_{6} \cdot \mathrm{A}_{\mathrm{w}}
\end{aligned}
$$

\section{IV.2.3: The Storage Batteries}

The design variable in the case of storage batteries is their capacity $C_{b}$ in kilo watt hours. As in the case of wind turbine, the lifetime of a battery $L_{b}$ is expected to be less than that of the whole project. Hence, batteries of capacity $C_{b}$ are to be purchased at regular intervals of $L_{b}$. The total PW of the capital and replacement investments in batteries is given by:

$$
\mathrm{I}_{3}+\mathrm{R}_{\mathrm{PW} 3}=\alpha_{\mathrm{b}} \cdot \mathrm{C}_{\mathrm{b}} \sum_{x=1}^{X_{\mathrm{b}}}\left(\frac{(1+\varepsilon g]^{(x-1) u_{\mathrm{b}}}}{(1+r)^{(x-1) v_{\mathrm{b}}}}\right)
$$

Where $L_{b}$ is the battery lifetime, $X_{b}$ is the number of times batteries should be purchased during the project lifetime: $X_{b}=N / L_{b}$ (rounded to the greater integer), and $\alpha_{b}$ is the capital cost in (Rs./kWh). The salvage value of the batteries is assumed to be negligible. With a yearly operation and maintenance cost of $\alpha_{\mathrm{OMb}}(\mathrm{Rs} . / \mathrm{kWh} / \mathrm{year})$, the total yearly operation and maintenance cost would be $\mathrm{OM}_{3}=\alpha_{\mathrm{OMb}} . \mathrm{C}_{\mathrm{b}}$, and the PW of all the yearly costs would be:

$$
\mathrm{OM}_{\mathrm{PW} 3}=\alpha_{\mathrm{OMb}} \cdot \mathrm{C}_{\mathrm{b}} \cdot \text { fac2 }
$$

In summary, the PWs of the battery costs are:

$$
\begin{gathered}
\mathrm{I}_{3}+\mathrm{R}_{\mathrm{PW} 3}=\alpha_{\mathrm{b}} \cdot \mathrm{C}_{\mathrm{b}} \sum_{x=1}^{X_{\mathrm{b}}} \cdot\left(\frac{(1+\varepsilon s)^{(x-1) v_{\mathrm{b}}}}{\left.(1+\eta)^{(x-1) y_{\mathrm{b}}}\right)=\mathrm{c}_{7} \cdot \mathrm{C}_{\mathrm{b}}}\right. \\
\mathrm{OM}_{\mathrm{PW} 3}=\alpha_{\mathrm{OMb}} \cdot \mathrm{C}_{\mathrm{b}} \cdot \mathrm{fac} 2=\mathrm{c}_{8} \cdot \mathrm{C}_{\mathrm{b}} \\
\mathrm{S}_{\mathrm{PW} 3}=0
\end{gathered}
$$

\section{IV.3. System Modeling}

Modeling is an essential step before any phase of optimal sizing. For the proposed PV-wind hybrid system with a storage battery, as shown in Figure 2, three principal subsystems are included, the PV array, the wind turbine generator (WTG), and the battery storage. 


\section{IV.3.1: Modeling of the PV Array}

For a PV array having an efficiency $\eta_{\mathrm{PV}}$ and area $A_{P V}\left(\mathrm{~m}^{2}\right)$, the output power $P_{P V}(\mathrm{~kW})$, when subjected to the available solar insolation $R\left(\mathrm{~kW} / \mathrm{m}^{2}\right)$ on the tilted surface, is given by [11]

$$
\mathrm{P}_{\mathrm{PV}}=\mathrm{R} \cdot \mathrm{A}_{\mathrm{PV}} \cdot \eta_{\mathrm{PV}}
$$

Here, the insolation $R$ incident on the PV array is defined in Figure 3 .

\section{IV.3.2: Modeling of the WTG}

A WTG produces power $P_{w}$ when the wind speed $V$ is higher than the cut-in speed $V_{c i}$ and is shut-down when $V$ is higher than the cut-out speed $V_{c o}$. When $V_{r}<V<V_{c o}\left(V_{r}\right.$ is the rated wind speed), the WTG produces rated power $P_{r}$. If $V_{c i}<V<V_{r}$, the WTG output power varies according to the cube law. The following equations are to be used in order to model the WTG $[7,13]$

$$
\mathbf{P}_{\mathrm{W}}=\left\{\begin{array}{c}
P_{r} \cdot\left(\frac{V^{3}-V_{c i}^{3}}{V_{r}^{3}-V_{c i}^{3}}\right), \quad V_{c i} \leq V \leq V_{r} \\
P_{r}, \quad V_{r} \leq V \leq V_{c o} \\
0, \quad V_{c o} \leq V \text { or } V \leq V_{c i}
\end{array}\right.
$$

Where

$$
\mathrm{P}_{\mathrm{r}}=\frac{1}{2} \mathrm{C}_{\mathrm{P}} \rho_{\text {air }} \mathrm{A}_{\mathrm{w}} V_{\gamma}^{\mathrm{a}}
$$

In the above equation, $C_{p}, \rho_{\text {air }}$, and $A_{w}$ are the power coefficient, air density, and rotor swept area, respectively. As the available wind speed data $V_{i}$ (see Figure 4) were estimated at a height $H_{i}=42$ feet/12.8 m, then to upgrade these data to a particular hub height $\mathrm{H}$, the following equation is commonly used $[1,7]$

$$
\mathrm{V}=\mathrm{V}_{\mathrm{i}} \cdot\left(\frac{H^{a}}{H_{i}^{a}}\right)
$$

Where $V$ is the upgraded wind speed at the hub height $H$ and $a$ is the power-law exponent $(\approx 1 / 7$ for open land).

\section{IV.3.3: Modeling of the Storage Battery}

At any hour $t$, the state of charge of the battery [SOC $(t)]$ is related to the previous state of charge [SOC $(t-1)$ ] and to the energy production and consumption situation of the system during the time from $t-1$ to $t$. During the charging process, when the battery power $P_{B}$ flows toward the battery (i.e., $P_{B}>0$ ), the available battery state of charge at hour $t$ can be described by:

$$
\operatorname{SOC}(\mathrm{t})=\operatorname{SOC}(\mathrm{t}-1)+\frac{p_{B}(\mathrm{t}) x \Delta t}{1000 x \mathrm{c}_{\mathrm{b}}}
$$

Where $\Delta \mathrm{t}$ is the simulation step time (which is set equal to 1 hour), and $C_{b}$ is the total nominal capacity of the battery in kilowatt-hours. On the other hand, when the battery power flows outside the battery (i.e., $\mathrm{P}_{\mathrm{B}}<0$ ), the battery is in discharging state. Therefore, the available battery state of charge at hour $t$ can be expressed as:

$$
\operatorname{SOC}(\mathrm{t})=\operatorname{SOC}(\mathrm{t}-1)-\frac{p_{B}(\mathrm{t}) x \Delta \mathrm{t}}{1000 x c_{\mathrm{b}}}
$$

To prolong the battery life, the battery should not be over discharged or overcharged. This means that the battery SOC at any hour $t$ must be subject to the following constraint:

$$
\left(1-D O D_{\max }\right) \leq \mathrm{SOC}(\mathrm{t}) \leq S O C_{\max }
$$

Where $\mathrm{DOD}_{\max }$ and $\mathrm{SOC}_{\max }$ are the battery maximum permissible depth of discharge and SOC, respectively.

\section{SYSTEM RELIABILITY AND SIMULATION}

First of all, it is assumed, in this work, that the peak power trackers, the battery charger/discharger, and the distribution lines are ideal (i.e., they are lossless). Also, it is assumed that the inverter efficiency $\eta_{i n v}$ is constant; the battery charge efficiency $\eta_{b}$ is set to equal to the manufacturers' round-trip efficiency, and the battery discharging efficiency is set to be 1 . The total generated power by the PV array and WTG for hour $t$, $P_{g}(\mathrm{t})$, can be expressed as

$$
P_{g}(t)=P_{P V}(t)+P_{w}(t)
$$

It is to be noted that the desired load demand at any hour $t, \mathrm{P}_{\mathrm{L}}^{*}(\mathrm{t})$, may or may not be satisfied according to the corresponding values of the total generated power $P_{g}(\mathrm{t})$ and the available battery SOC(t) at that hour. The proposed energy management of the $\mathrm{PV}$-wind hybrid system can be summarized as follows:

- If $\left[P_{\mathrm{g}}(\mathrm{t})>\mathrm{P}_{\mathrm{L}}{ }^{*}(\mathrm{t}) / \eta_{\text {inv }}\right]$ and $[\mathrm{SOC}(\mathrm{t}-1)<\mathrm{SOCmax}]$ then satisfy the load and charge the battery [using Equation (20)] with the surplus power $\left[P_{B}(\mathrm{t})=\left(P_{g}(\mathrm{t})-\mathrm{P}_{\mathrm{L}}^{*}(\mathrm{t}) / \eta_{\text {inv }}\right) \eta_{\mathrm{b}}\right]$. Afterwards, check if $[\mathrm{SOC}(\mathrm{t}) \geq \mathrm{SOCmax}]$ then stop battery charging, set $\mathrm{SOC}(\mathrm{t})=\mathrm{SOCmax}$, and dump the surplus power $\left(P_{\text {Dump }}(\mathrm{t})=\operatorname{Pg}(\mathrm{t})-\left[\mathrm{P}_{\mathrm{L}}{ }^{*}(\mathrm{t}) /\right.\right.$ $\left.\left.\eta_{i n v}+1000 \times C_{b} / \Delta \mathrm{t} \times \eta_{\mathrm{b}} \times(\operatorname{SOCmax}-\mathrm{SOC}(\mathrm{t}-1))\right]\right)$. 
- If $\left[P_{\mathrm{g}}(\mathrm{t})>\mathrm{P}_{\mathrm{L}}{ }^{*}(\mathrm{t}) / \eta_{\text {inv }}\right]$ and $[\mathrm{SOC}(\mathrm{t}-1) \geq \mathrm{SOCmax}]$ then stop charging the battery, satisfy the load, and dump the surplus power $\left[P_{\text {Dump }}(\mathrm{t})=P_{\mathrm{g}}(\mathrm{t})-\mathrm{P}_{\mathrm{L}}^{*}(\mathrm{t}) / \eta_{\text {inv }}\right]$.

- If $\left[P_{\mathrm{g}}(\mathrm{t})=\mathrm{P}_{\mathrm{L}}^{*}(\mathrm{t}) / \eta_{\text {inv }}\right]$ then satisfy the load only.

- If $\left.\left[P_{\mathrm{g}}(\mathrm{t})<\mathrm{P}_{\mathrm{L}}{ }^{*} \mathrm{t}\right) / \eta_{\text {inv }}\right]$ and $\left[\mathrm{DOD}(t-1)<\mathrm{DOD}_{\max }\right]$ then satisfy the load by discharging the battery [using Equation (21)] to cover the deficit in load power $\left[P_{B}(\mathrm{t})=\mathrm{P}_{\mathrm{L}}^{*}(\mathrm{t}) / \eta_{i n v}-P_{\mathrm{g}}(\mathrm{t})\right]$. Afterwards, check if $\left[\mathrm{DOD}(t) \geq \mathrm{DOD}_{\max }\right]$ then stop battery discharging, set $\mathrm{DOD}(\mathrm{t})=\mathrm{DODmax}$, and calculate the deficit in load power $\left(\mathrm{P}_{\text {deficit }}(\mathrm{t})=\mathrm{P}_{\mathrm{L}}^{*}(\mathrm{t})-\left[P_{\mathrm{g}}(\mathrm{t})+1000 \times C_{b} / \Delta \mathrm{t} \times(\mathrm{SOC}(\mathrm{t}-1)-(1-\mathrm{DODmax}))\right] \eta_{\text {inv }}\right.$.

- If $\left[P_{\mathrm{g}}(\mathrm{t})<\mathrm{P}_{\mathrm{L}}{ }^{*}(\mathrm{t}) / \eta_{\text {inv }}\right]$ and $\left[\mathrm{DOD}(t-1) \geq \mathrm{DOD}_{\max }\right]$ then stop battery discharging and $\left[\mathrm{P}_{\text {deficit }}(\mathrm{t})=\mathrm{P}_{\mathrm{L}}{ }^{*}(\mathrm{t})-P_{\mathrm{g}}(\mathrm{t})\right.$. $\eta_{\text {inv. }}$.

As it is assumed, in this work, the simulation step time $\Delta \mathrm{t}$ is equal to $1 \mathrm{~h}$ and the generated PV and wind powers are constants during $\Delta \mathrm{t}$ Then, the power is numerically equal to the energy within $\Delta \mathrm{t}$. A flowchart diagram for this program is shown in Figure 6. The input data for this program consist of mean hourly global insolation on a tilted array $R$, mean hourly wind speed $V_{i}$, and desired load power during the year $P_{L}{ }^{*}$. Note, here, that for every configuration of the proposed PV-wind hybrid system, this program simulates the system. There are three additional bounds that should be imposed on the sizes of the system components, which are:

$$
\begin{aligned}
& 0 \leq \mathrm{A}_{\mathrm{PV}} \leq \mathrm{A}_{\mathrm{PV} \max } \\
& 0 \leq \mathrm{A}_{\mathrm{w}} \leq \mathrm{A}_{\mathrm{w} \text { max }} \\
& 0 \leq \mathrm{C}_{\mathrm{b}} \leq \mathrm{C}_{\mathrm{b} \text { max }}
\end{aligned}
$$

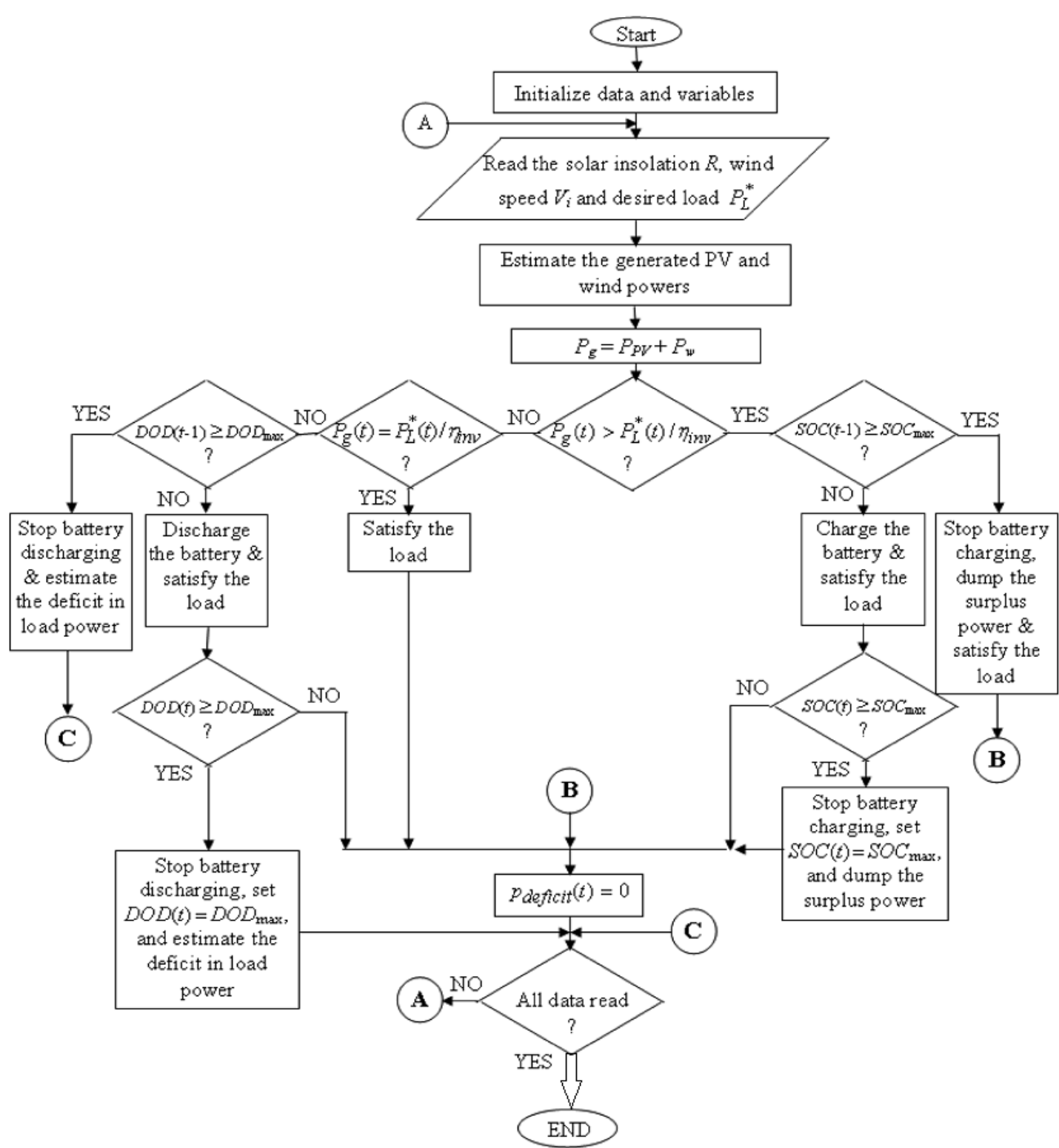

Figure -6: Flow-chart of the simulation Program 


\section{FINAL FORM AND GA OPTIMIZATION}

At this stage, the optimization problem can be written in its final form as follows:

1. Minimize the cost function $\mathrm{C}_{\mathrm{T}}$

2. Subject to:

$$
\left(\mathrm{c}_{1}+\mathrm{c}_{2}-\mathrm{c}_{3}\right) \cdot A_{P V}+\left(\mathrm{c}_{4}+\mathrm{c}_{5}-\mathrm{c}_{6}\right) \cdot A_{W}+\left(\mathrm{c}_{7}+\mathrm{c}_{8}\right) \cdot C_{b}
$$

$$
\begin{gathered}
0 \leq A_{P V} \leq A_{P V \max } \\
0 \leq A_{w} \leq A_{w \text { max }} \\
0 \leq C_{b} \leq C_{b \text { max }}
\end{gathered}
$$

To solve the above optimization problem, GA is proposed, where, in this work, the Genetic Algorithm Code under MATLAB software is utilized for solving the previous optimization problem. GA contains the elitist approach. This means that a solution cannot degrade from one generation to the next, but that best individual of a generation is copied to the next generation without any changes being made to it. To use the GA, for solving the formulated optimization problem, a M-file (MATLAB Code) has written, to compute the values of the objective function (or called fitness function). The M-file has to be written to accept a vector (i.e., individual) whose length is the number of independent variables for the objective function and return the corresponding scalar values of the objective function (i.e., cost). In this work, the individual of the considered optimization problem contains three variables (or genes), which are: $\mathbf{A}_{\mathbf{P V}}, \mathbf{A}_{\mathbf{w}}$, and $\mathbf{C}_{\mathbf{b}}$. The used GA is based upon using the flowchart of Figure 7, to yield the optimal solution. Initially, the GA selects individuals at random from the current population to be parents and uses them to produce the children for the next generation by using the three main operations, which are the selection, crossover, and mutation operations. Then, it can repeatedly modify a population of individual solutions, where, over successive generations, the population evolves toward an optimal solution. Note, here, that the used different settings in the GA are 100 individuals for the population size, the stochastic uniform function for the selection operation, the scattered crossover function (with a crossover probability of $80 \%$ ) for the crossover operation, the adaptive feasible mutation function (with a probability rate of $1 \%$ ) for the mutation operation, and an elite individual. At the same time, it is to be noted that the additional three bounds of Equation (28) can be entered directly in the dedicated positions of the GA.

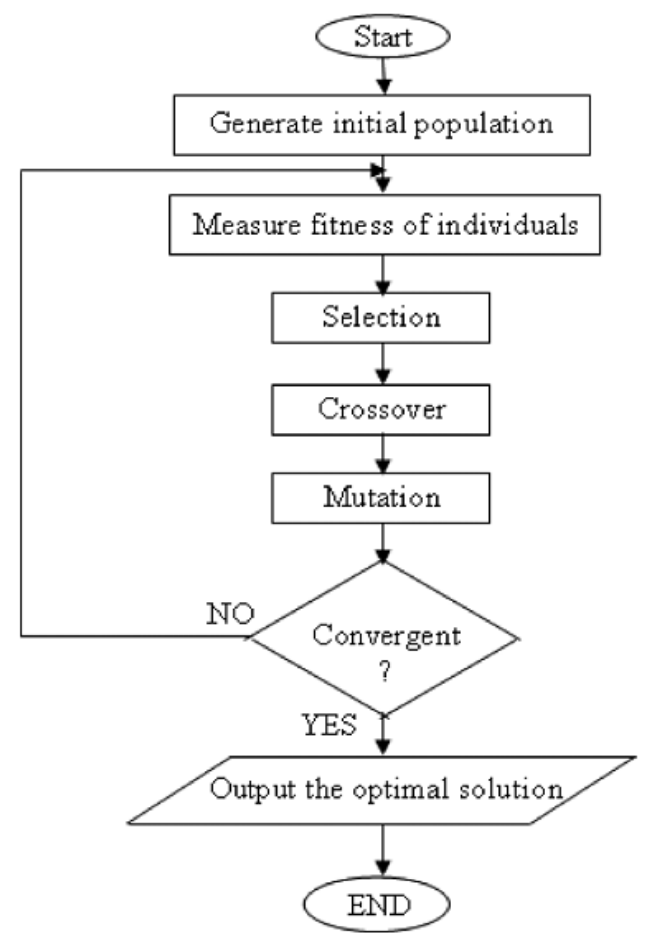

Figure -7: Flow-chart of the Genetic Algorithm (GA)

VII.

APPLICATION RESULTS AND DISCUSSION

The formulated optimization problem of the PV-wind hybrid energy system is solved, in this work, by using the GA under MATLAB software, which may provide a number of potential solutions to the given problem. The choice of the final optimum solution is left to the system's designer. The specifications and the related maintenance and installation costs of different wind turbines, PV panels and batteries, which are input to the optimal sizing procedure, are listed in Tables I-III. The maintenance cost of each unit per year and the 
installation cost of each component have been set at $0-1 \%$ and $5-10 \%$ respectively of the corresponding cost. The life time of Wind Turbine, PV panel and Battery is considered to be 5 years. Since the tower heights of wind turbines affect the results significantly, $12.8 \mathrm{~m}$ meter high tower at an elevation of $1829 \mathrm{~m}$ is chosen. The minimization of the system total cost is achieved by selecting an appropriate system configuration. In table IV, it indicates the resulted optimum sizes of the different components included in the hybrid system. The corresponding fitness function optimization (i.e., minimization of the system cost in rupees) along the successive generations of the GA is shown in Figure 8, which indicates that the system is optimized after forty iterations only.

Table-I: Wind Turbine Data

\begin{tabular}{|c|c|}
\hline Power Rating $(\mathrm{W})$ & 2500 \\
\hline$V_{r}(\mathrm{~m} / \mathrm{s})$ & 30 \\
\hline$V_{c i}(\mathrm{~m} / \mathrm{s})$ & 15 \\
\hline$V_{c o}(\mathrm{~m} / \mathrm{s})$ & 40 \\
\hline Life Time of the WTG (years) & 5 \\
\hline Installation Cost (Rs./ $\left.\mathrm{m}^{2}\right)$ & 17 \\
\hline $\begin{array}{c}\text { Operation and Maintenance Cost (Rs. } \\
\text { /yr.) }\end{array}$ & 3.4 \\
\hline
\end{tabular}

Table-III: Battery Specifications

\begin{tabular}{|c|c|}
\hline Nominal Capacity (Ah) & 50 \\
\hline Voltage (V) & 12 \\
\hline DOD (\%) & 80 \\
\hline Efficiency (\%) & 80 \\
\hline Life Time of the PV Panel (years) & 5 \\
\hline Installation Cost (Rs. $/ \mathrm{m}^{2}$ ) & 13 \\
\hline Operation and Maintenance Cost (Rs. $/$ yr.) & 2.6 \\
\hline
\end{tabular}

Table- II: PV Array Data

\begin{tabular}{|c|c|}
\hline$V_{o c}(\mathrm{~V})$ & 2500 \\
\hline$I_{s c}(\mathrm{~A})$ & 30 \\
\hline $\begin{array}{c}\text { Life Time of the PV Panel } \\
\text { (years) }\end{array}$ & 5 \\
\hline Installation Cost $\left(\right.$ Rs. $\left./ \mathrm{m}^{2}\right)$ & 5.5 \\
\hline $\begin{array}{c}\text { Operation and Maintenance } \\
\text { Cost (Rs. } / \mathrm{yr} \text {.) }\end{array}$ & 0.65 \\
\hline
\end{tabular}

Table- IV: Optimum sizes of the hybrid System

\begin{tabular}{|l|l|l|}
\hline $\mathrm{ApV}_{(}\left(\mathrm{m}^{2}\right)$ & $\mathrm{A}_{\mathrm{W}}\left(\mathrm{m}^{2}\right)$ & $\mathrm{C}_{\mathrm{b}}(\mathrm{kWh})$ \\
\hline 40.0004 & 50.0000 & 30.0000 \\
\hline
\end{tabular}

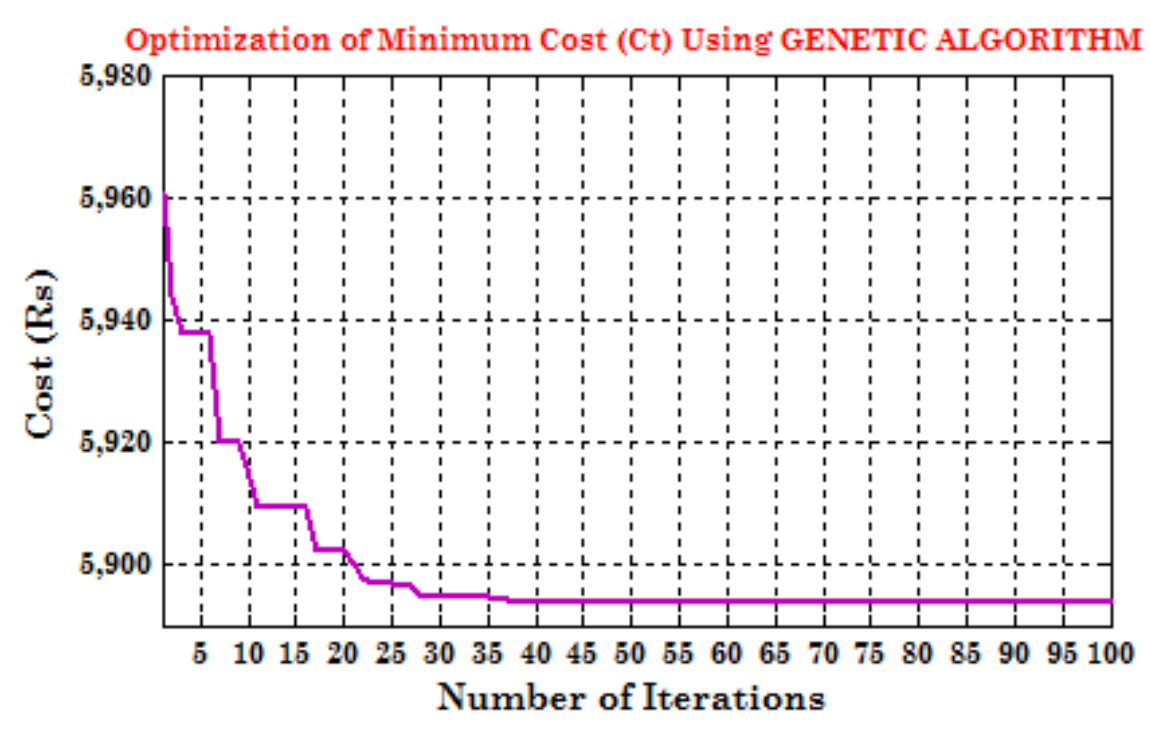

Figure -8: Optimization of the Objective function using GA

The combination of PV and wind in a hybrid energy system reduces the battery bank and diesel requirements; therefore the system total cost is reduced. Table-V shows a comparison between the costs that resulted from solving the formulated optimization problem by using the proposed GA-based technique and the TLBO algorithm using MATLAB software, Thus, Table-V indicates that the proposed GA-based technique is better than the TLBO algorithm, in solving such optimization problems, and this is due to the fact that the GA is capable to converge to the global optimum solution instead of convergent at a local optimum one. Teachinglearning is an important process where every individual tries to learn something from other individuals to improve himself / herself. It is an algorithm known as teaching-learning based optimization (TLBO) [18] which 
simulates the traditional teaching-learning phenomenon of the classroom. The algorithm simulates two fundamental modes of learning: (i) through teacher (known as teacher phase) and (ii) interacting with the other learners (known as the learner phase). TLBO is a population based algorithm where a group of students (i.e. learners) is considered as population and the different subjects offered to the learners is analogous with the different design variables of the optimization problem. The grades of a learner in each subject represent a possible solution to the optimization problem (value of design variables) and the mean result of a learner considering all subjects corresponds to the quality of the associated solution (fitness value).The best solution in the entire population is considered as the teacher. In another M-file a MATLAB code has written for proposed hybrid PV/Wind energy system using Teaching Learning Based Optimization (TLBO) algorithm. The corresponding fitness function optimization (i.e., minimization of the system cost in rupees) along the successive iterations of the TLBO is shown in Figure 9, which indicates that the system is not optimized even after hundred iterations.

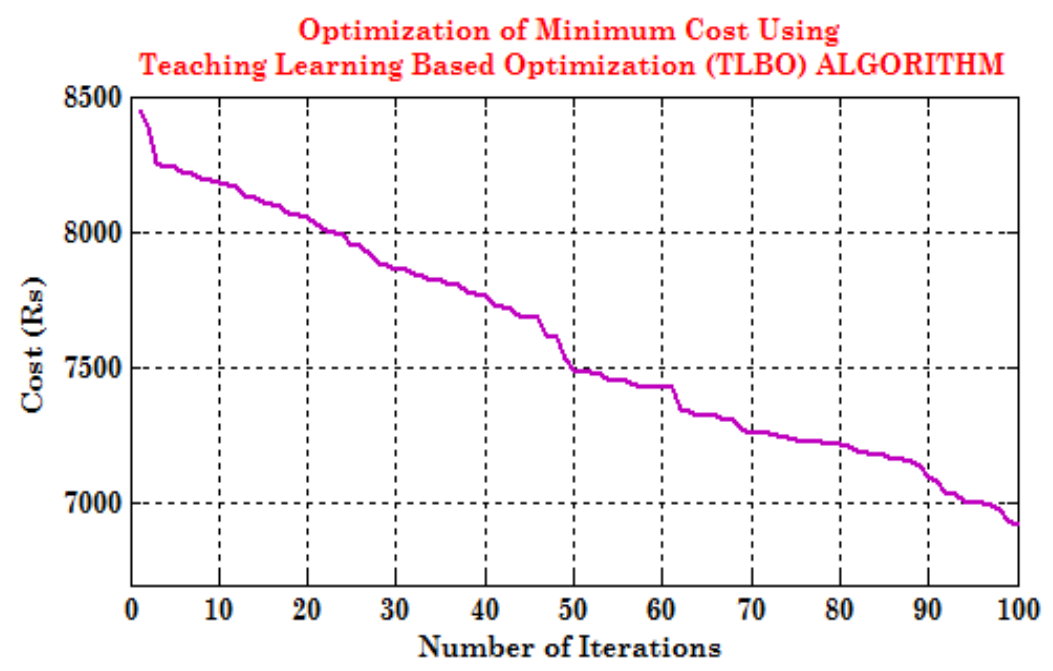

Figure -9: Optimization of the fitness function using TLBO

Table- V: Cost comparison using GA and TLBO

\begin{tabular}{|c|c|}
\hline Technique & Cost (Rs.) \\
\hline Genetic Algorithm (GA) & 5,893 \\
\hline Teaching Learning Based Optimization (TLBO) & 6,968 \\
\hline
\end{tabular}

Figure 10, 11, and 12 illustrates the generated PV power, wind power, and the total generated power of the suggested PV-wind hybrid system, for every month during the year.

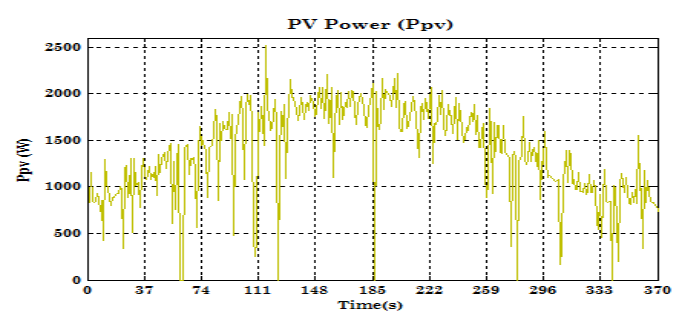

Figure-10: PV Power

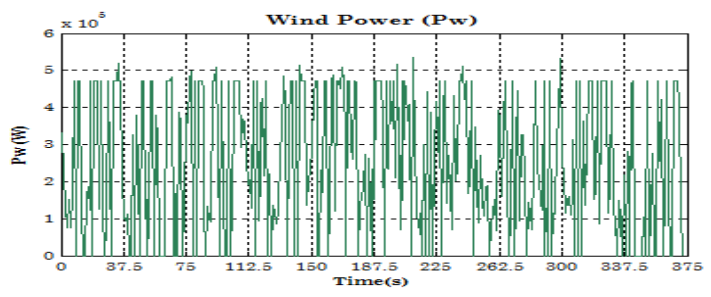

Figure-11: Wind Power

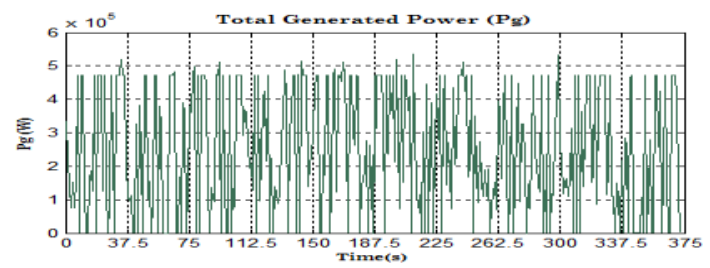

Figure -12: Total generated Power 


\section{VIII.CONCLUSIONS}

This paper presents a GA-based optimization technique to optimally size a proposed PV-wind hybrid energy system, incorporating a storage battery. The optimization problem is formulated, in this work, to achieve a minimum total cost for the system components and to ensure that the load is served reliably. The results yield that the GA converges very well and the proposed technique is feasible for sizing either of the PV-wind hybrid energy system, stand-alone PV system, or stand-alone wind system. In addition, the proposed technique is able to be adjusted if insolation, wind speed, load demand, and initial cost of each component participating in the system are changed. The results yield, also, that the PV-wind hybrid energy systems are the most economical and reliable solution for electrifying remote area loads.

\section{REFERENCES}

[1]. Kellogg, W.D., M.H. Nehrir, G. Venkataramanan, and V. Gerez. 1998. Generation unit sizing and cost analysis for stand-alone wind, photovoltaic, and hybrid wind/PV systems. IEEE Trans. on Energy Conversion 13(1): 70-75.

[2]. Gupta, A., R.P. Saini, and M.P. Sharma. 2007. Design of an optimal hybrid energy system model for remote rural area power generation. In Proceedings of the IEEE International Conference on Electrical Engineering (ICEE 2007), Lahore, Pakistan, 1-6.

[3]. Hongxing, Y., Z. Wei, and L. Chengzhi. 2009. Optimal design and techno-economic analysis of a hybrid solar-wind power generation system. Applied Energy 86: 163-169.

[4]. Roman, E., R. Alonso, P. Ibanez, S. Elorduizapatarietxe, and D. Goitia. 2006. Intelligent PV module for grid-connected PV systems. IEEE Transactions on Industrial Electronics 53(4):1066-1073.

[5]. Colle, S., S. Luna, and R. Ricardo. 2004. Economic evaluation and optimization of hybrid diesel/PV systems integrated to utility grids. Solar Energy 76: 295-299.

[6]. Wies, R.W., R.A. Johnson, A.N. Agrawal, and T.J. Chubb. 2005. Simulink model for economic analysis and environmental impacts of a PV with diesel-battery system for remote villages. IEEE Transactions on Power Systems 20(2): 692-700.

[7]. Borowy, B.S., and Z.M. Salameh. 1996. Methodology for optimally sizing the combination of a battery bank and PV array in a wind/PV hybrid system. IEEE Transactions on Energy Conversion 11(2): 367375.

[8]. Prasad, A.R., and E. Natarajan. 2006. Optimization of integrated photovoltaic-wind power systems with battery storage. Energy 31: 1943-1954.

[9]. Shaahid, S.M., and M.A. Elhadidy. 2008. Economic analysis of hybrid photovoltaic-diesel-battery power systems for residential loads in hot regions-a step to clean future. Renewable and Sustainable Energy Reviews 12: 488-503.

[10]. Ai, B., H. Yang, H. Shen, and X. Liao. 2003. Computer aided design of PV/wind hybrid system. Renewable Energy 28: 1491-1512.

[11]. Diaf, S., D. Diaf, M. Haddadi, and A. Louche. 2007. A methodology for optimal sizing of autonomous hybrid PV/Wind system. Energy Policy 35: 5708-5718.

[12]. Senjyu, T., D. Hayashi, N. Urasaki, and T. Funabashi. 2006. Optimum configuration for renewable generating systems in residence using genetic algorithm. IEEE Transactions on Energy Conversion 21(2): 459-466.

[13]. Yang, H., L. Lu, and W. Zhou. 2007. A novel optimization sizing model for hybrid solar-wind power generation system. Solar Energy 81: 76-84.

[14]. Karaki, S.H., R.B. Chedid, and R. Ramadan. 1999. Probabilistic performance assessment of autonomous solar-wind energy conversion systems. IEEE Transactions on Energy Conversion 14(3): 766-772.

[15]. Chedid, R., H. Akiki, and S. Rahman. 1998. A decision support tech. for the design of hybrid PV/wind systems. IEEE Transactions on Energy Conversion 13: 76-82.

[16]. Sweelem, E.A., and A.A. Nafeh. 2006. A linear programming technique for optimally sizing a PV-dieselBattery hybrid energy system. Al-Azhar University Engineering Journal 9(3): 705-716.

[17]. Xu Daming, Kang Longyun, Cao Binggang, "Stand-alone hybrid wind/PV power system using the NSGA2," Acta energiae solaris sinica, vol. 27, no. 6, pp.593-598, 2006.

[18]. R. V. Rao, V. J. Savsani and D. P. Vakharia, "Teaching- Learning-Based Optimization: A Novel Method for Con-strained Mechanical Design Optimization Problems," Computer-Aided Design, Vol. 43, No. 1, 2011, pp. 303- 315. doi:10.1016/j.cad.2010.12.015. 